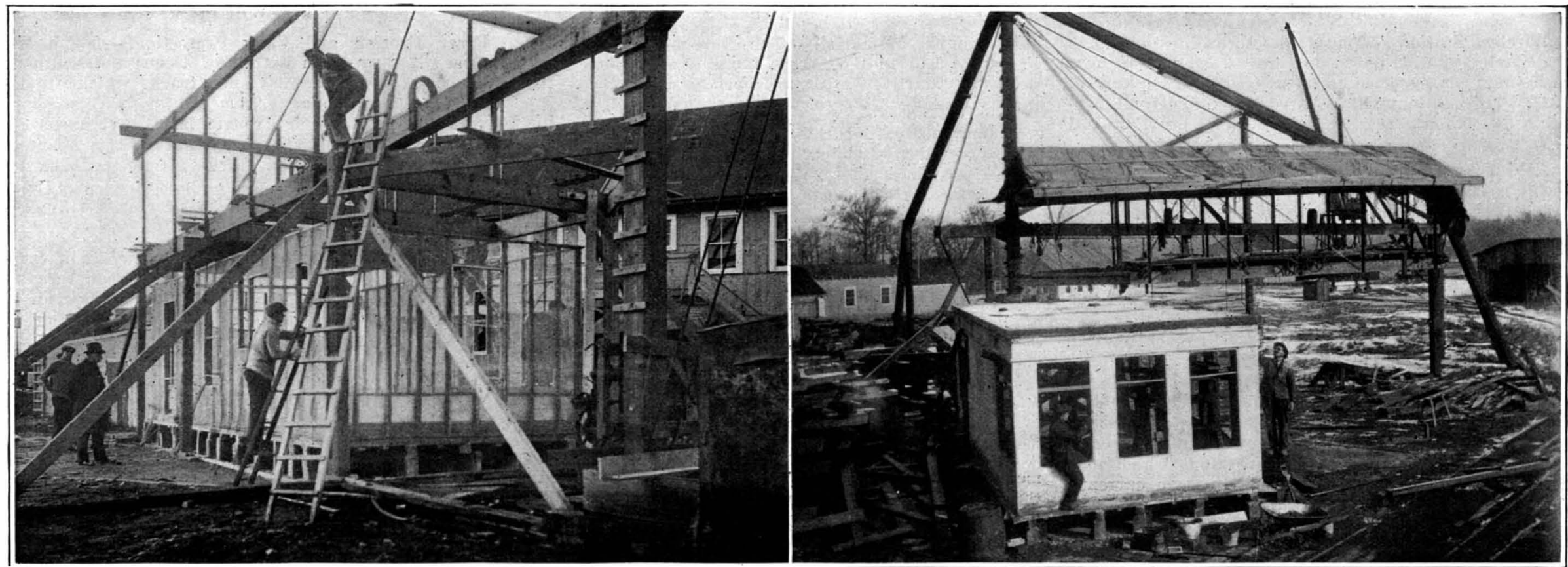

Two stages in the manufacture of the Lake concrete unit dwellings which are completed with plumbing, wiring and other accessories before shipment
to the buyer

\title{
The One-Piece House
}

Simon Lake's Scheme for Producing Ready-to-Live-In Concrete Unit Dwellings and Transporting Them to the Site By Harry A. Mount

W HEN one recalls the wide heraldry given a few years ago to the schem of Thomas Edison for building monolithic cement houses from forms or molds that were to be used over and over again, one is warned to hold within bounds his enthusiasm over similar projects. The Edison scheme was practical-is practical, in fact, and being used here and there on a small scale. It has not been applied on a universal scale, as was so confidently expected. Now comes Simon Lake of tor pedo boat fame, who says he has found and removed the flaws in Edison's plan and is preparing to put his new schem into effect on a nation-wide scale.

The most remarkable part of $\mathrm{Mr}$. Lake's scheme is that, instead of building the house on the lot, necessitating a vast amount of labor for putting up and tearing down expensive forms, he will buil monolithic concrete units from standardized forms in well-equipped factories, and deliver the finished house, ready for occupancy, to the lot

At first thought there seems to be insurmountable difficulties to any such proposition. How could a concrete house, no matter how small, be built light enough and at the same time strong enough for transportation But supposing that were possible, where could we find a vehicle that would pick up and carry a house of any size a reasonable distance without prohibitive cost?

In finding an answer to these questions, Mr. Lake and his collaborator in the enMr. Lake and hort C. Lafferty, a New York terprise, Robert C. Lafferty, a New York architect, have departed so far from
standard practise that they have had to manufacture their own engineering data as they went, and some of their answers are nothing short of startling.

For instance, the walls, floors and ceilings of the house are hollow, with only $3 / 8$-inch thickness of cement on the inside and 5 -inch on the outside. And yet a house of this construction has stood tests more severe than if it had passed through a half-dozen San Francisco earthquakes without a crack or a sign of structural weakness.

These tests included transportation by motor truck five miles at speeds up to 15 miles an hour. And such a motor truck! It is a specially designed tenwheel affair, which carries the house swung low on a structural steel cradle. It is equipped with hoists, and other machinery for handling the house in put-

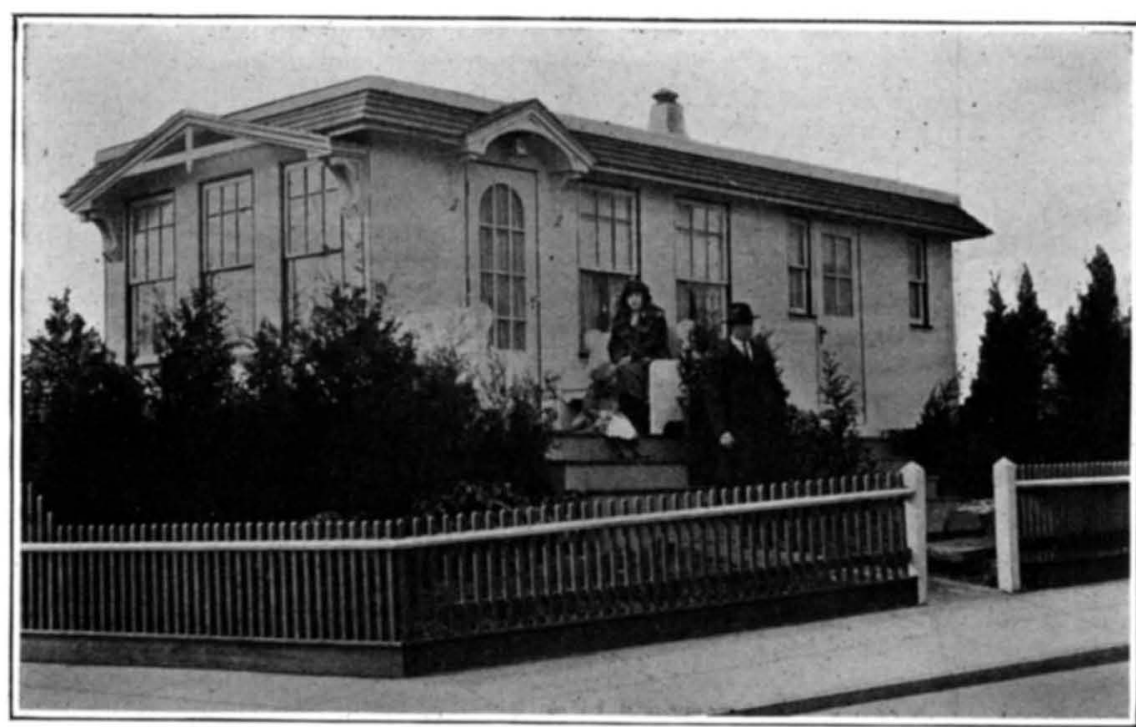

A single unit dwelling built by the Lake method and subjected to numerous tests with marked success house, they are hardly less so than the architectural features, the work of $\mathrm{Mr}$ Lafferty. By the application of a number of ingenious devices one unit of this construction, measuring $121 / 2$ by $281 / 2$ feet, is made to serve all the practical purposes of a five-room house.

In a house built of more than one unit, the feature which first recommends itself is the infinite variety of combinations and finishes possible in treating both the interior and exterior. Doors, windows, walls, etc., are not arbitrarily fixed, and the effects may be varied to suit individual taste. In fact, the only limiting factor in design is the size of the units, although two of them may be combined to form a single large room. Thus it is possible to produce from these units a tiny dwelling, a mansion, or a five- or six-family apartment house.

In this connection the one-unit house is of particular interest, for it represents housing reduced to its lowest terms. These units will sell, complete and delivered on to the foundation, for as little as $\$ 1,500$.

The front door opens into a little vestibule, with a coat closet. The center of ting it on and taking it off the truck. It is believed that the house is occupied by a combined dining and living two men can load, deliver and set up a house complete room, although ordinarily there is no hint that it is within a radius of fifty miles of the factory in one day. used for meals. A large mirror on one wall, when As startling as are the engineering features of the swung down and rested on two folding legs, becomes the dining room table. This discloses, behind the mirror, a revolving server which communicates with the kitchen. When the meal is finished the dishes are piled on the server and when this is revolved they are transferred to the kitchen at the sink. The kitchen contains besides the sink a four-burner gas stove and oven, refrigerator and an electric washer. Opposite the kitchen door is the bath, fully equipped. At one end of the house, off the living room, is a small sun room with a built-in window seat. Communicating with this is a small dressing room. At the other end of the house is a den, with identical arrangement. In each of these two rooms full-sized beds disappear into the ceiling, the bottom of the bed serving as a large section of the ceiling. These beds are lowered by means of a crank in the dressing room, and at night one end rests on the window seat and the other on two folding legs.

Glass doors which may be used to shut off the sun room at night, slide back and 
form doors for book cases on either side of the doorway in the daytime. The heating plant is a small stove in a fireproof alcove off the hallway, and this has been found sufficient to heat the house in the coldest weather. Further plans include a coal bin on the roof, bolding two tons, arranged so that by pulling a lever the fuel drops directly into the stove.

The success of the scheme depends largely upon a unique method of construction, upon which Mr. Lake has been allowed broad basic patents. The central piece of apparatus of his unit dwelling is a huge traveling-factory, crane-like affair, on which are mounted two cement mixtures with loading hopper bins placed over them. The sand and cement are lifted to these hoppers from railroad cars, which run beneath the apparatus, by means of a grab bucket.

The cement, after mixing, flows by gravity into the forms. The frame of the house is first constructed of creosoted wood, on both sides of which is fastened heavy reinforcing netting. The window and door frames are then placed in position and the traveling plant moves to this position. There are two heary rood forms for both inside and outside walls, one on each side of the apparatus, so arranged as to counterbalance each other, so that when one is lowered the other is raised. One of these forms is dropped over the prepared reinforcing. As door and window frames ing it to its final location. Meanwhile the roof slab is placed on the four walls, the plumbing and electric wiring are completed, and the house finally finished for occupancy. Even the electric light fixtures are hung and window shades are in place when the house is finally loaded on to the big truck and trundled off The finished unit weighs about fifteen tons, but by means of the special truck it is readily handled by two men. If the house is to rest on piers, these are first placed and the truck then drives between them, elevates the house to the proper height and sets it down. The truck is then taken apart beneath the house and is withdrawn in two sections. These sections are subsequently reunited and the truck is ready for another trip.

The special motor truck carrier practically divides the load on two trucks comprising four forty-inch wheels each. The solid rubber tires are each fourteen inches wide, so that the hard road contact is about 350 pounds per inch. Where delivery is to be made over meadows or soft ground, a caterpillar belt will connect each adjoining pair of wheels, thus reducing the ground bearing to about 22 pounds to the square inch. The truck, it is claimed, will attain a speed of 14 miles an hour and, when fully underslung, will carr the units under an eleven-foot viaduct. The truck' elerating apparatus allows the delivery of the second and it is certainly no longer an economical material. "For many years cement has been recognized as an ideal building material if it can be thoroughly dampproofed, if there is some means to dispense with the cost and waste of forms, and if, also, the requisite omy can be obtained while producing homes in an infnite variety of architectural designs.

"We think our construction meets these requirements and others. The house, by our process, is thoroughly damp-proofed. It is also heat- and cold-proof, for the hollow walls are good insulators. The house is as nearly fireproof as it can be made; the upkeep expense is minimized for no painting nor roofing is ever required. The life of the building is several times that of a frame house. We use an abundant raw material and employ the most economical production methods. We use more unskilled labor than is the customary practice. We have, in our smaller units, recognized and solved the servant problem. Other units can be added as desired. In the one-unit house seventy-five per cent of the furniture is built in, eliminating extravagant furnishings,"

\section{One-Way British Motor Plows}

$\mathrm{A}^{\mathrm{MONG}}$ the most interesting of recent development $A$ in British agricultural engineering is the oneway motor plow, which has appeared upon the British

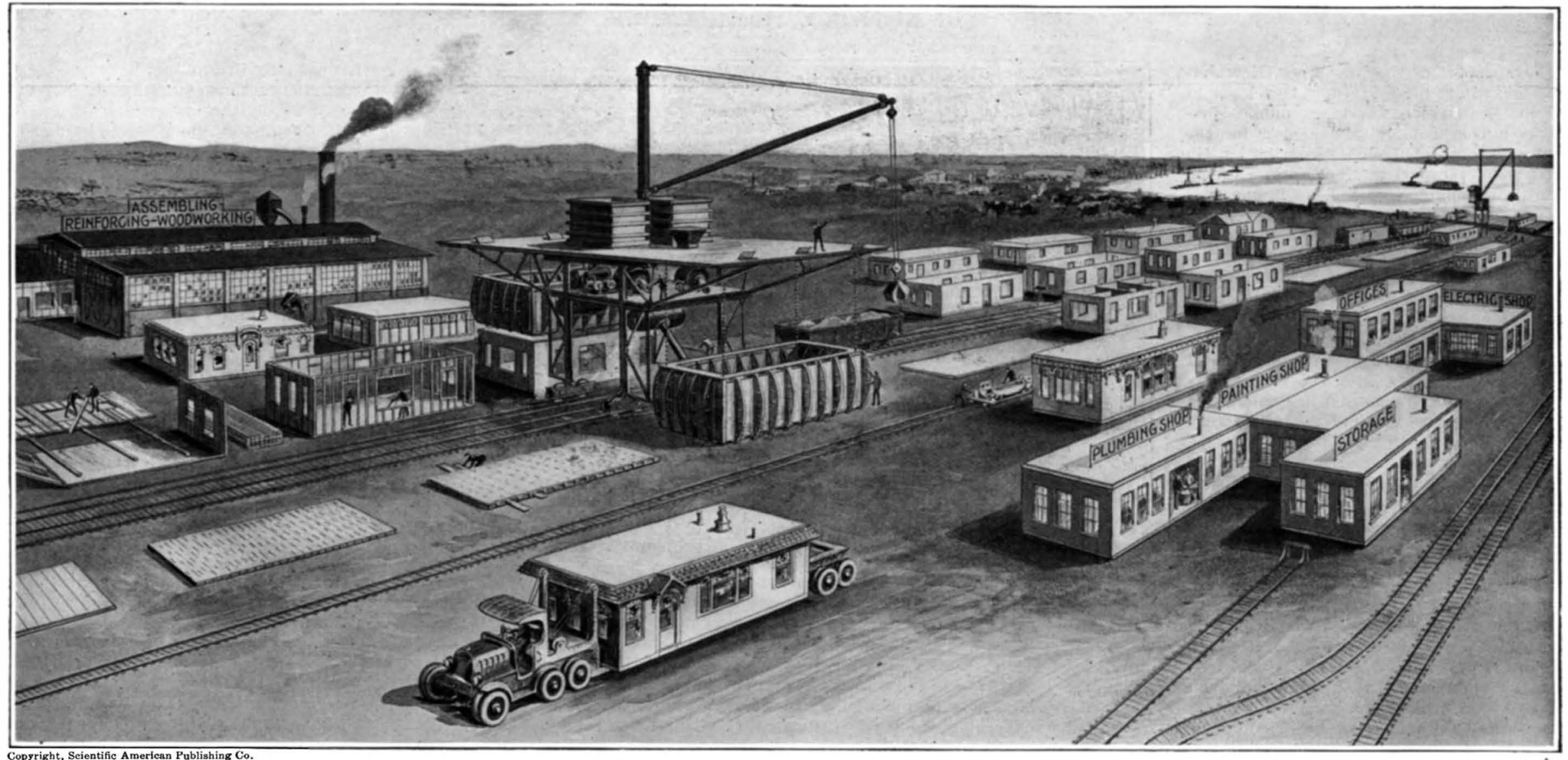

Bird's-eye view of a typical plant for producing the Lake concrete unit dwellings. In the center foreground appears one of the special trucks for transporting the unit dwellings in one piece

run through the walls, the frames seal these openings against cement.

The crucial part of the operation then begins. The walls are made hollow by placing in the forms the "cores" of heavy sheet iron, properly reinforced to prevent collapsing. Before placing these cores in position, they are dipped in a bath of asphalt until a coating nearly an eighth of an inch thick is deposited on them The cores are then placed in position and the cemen is poured.

Ordinarily it would be several days before the form could be removed, and the cores would then be so tightly imbedded in the cement that they could not be removed. But warm air, held at a temperature of 180 degrees, is at once circulated through the hollow cores and a threefold result is achieved. First, the cores and a threefold result is achieved. First, the cement is dehydrated and dried within two and a half
hours; secondly, the asphalt coating is melted so that the cores can be easily withdrawn; and thirdly, a heavy coating of asphalt is deposited on the inne lining of the walls, making them entirely water tight. What it readily absorbs liquids, a waterproof filler, so that it reac side walls. The house is then picked up by the traveling machine and deposited further down the yard where it is allowed to stand two weeks to allow the cement thoroughly to harden or season in order that the house may stand the handling necessary in transport- story of a two-story house first. It is elevated to the proper height and propped in position. The truck is withdrawn and returns with the first story unit, depositing it beneath. The second story is then lowered in place, on top of the first story.

The smallest economical plant will consist of one traveling cement machine, woodworking, plumbing and paint shops, and four delivery trucks. The plant will complete the units at the rate of four a day. For the first plant unit of this size an abandoned shipyard has been purchased at Bridgeport, Conn., and the plant is ready to begin production. It is planned to deliver within a radius of fifty miles of this factory without extra charge, and gradually to establish branch factories in other centers of population.

"Of course" said Mr. Lafferty, in discussing the new type of construction "no single invention or method will solve the housing problem. It is too big for that. We cannot hope to build more than a small percentage of all the houses that are immediately needed.

"Our chief aim has been to produce a home that anyone could afford to own. I think a good remedy for the present discontent is to encourage the 60 for the present discontent is to encourage the 60 pe ent of our citizens who now live in rented homes to own their own dwellings. But even the most mo

"First of all, the construction must be economical, n matter what it is. That excludes wood for we ar using wood four times faster than we are producing it market in the form-judging from field experimentsof a successful model. Upon a commercial basis, this and other one-way plows will soon make their appearance.

The one-way motor plow has features which recommend it to all farmers whose arable land is divided into comparatively small areas, as in this country, and also to those agriculturists abroad who require to economize the space left at the headlands. One-way plowing, moreover, is a simple procedure which native labor can follow with little preliminary guidance, for there is no demand upon the operator to exhibit skill in turning in a circumscribed area at the end of the furrow and simultaneously to lift the plow out of work. The reasons for the popularity of the one-way system, therefore, are obvious.

The one-way motor plow in the present case consists of six plow breasts, three being suspended from each end of the main carriage, which is modeled on the lines of a tractor body and is driven by an engine suffciently powerful to haul three furrows in the heaviest clay land. The forward shares are held out of work as the motor plow proceeds across the field and automatically drop into work when the machine begins its return journey. Plowing therefore becomes a succes sion of forward and return movements. One type of one-way plow has the advantage that it can be used as a tractor to haul another implement or a laden wagon, for the plows can be removed. 